\title{
Radiation Damage and Free Radical Production in Irradiated Ribonuclease
}

\author{
J. W. HUNT, J. E. TILL, AND J. F. WILLIAMS \\ Department of Medical Biophysics, University of Toronto, and The Ontario \\ Cancer Institute, Toronto, Canada
}

\section{INTRODUCTION}

It is probable that transient free radical states are implicated in the chain of events leading to the production of radiation damage. In solids and in dry biological materials, these free radicals are comparatively stable and have been studied by a number of workers in materials of biological interest, including biochemicals $(1,2)$, bacterial spores $(3)$, and seeds $(4,5)$. The objective of such studies has been to determine the extent to which free radical mechanisms are responsible for the biological effects of ionizing radiation. Unfortunately, from the radiobiological point of view, many of the studies utilizing pure compounds have been limited by the lack of an assayable biological activity, and studies of radiation effects on biologically active systems are often difficult to interpret because of the complexity of the systems at the molecular level.

Some of these difficulties may be avoided by using as a test system a biologically active macromolecule, either protein or nucleic acid. At the present time, the bestcharacterized of these macromolecules are the enzymes-in particular, the enzyme ribonuclease (RNase). In the experiments to be reported here, the radiation sensitivity of the enzymatic activity of RNase irradiated in the dry state in various gaseous environments has been studied, and a preliminary attempt has been made to relate these results to the electron spin resonance (ESR) spectra of the free radicals produced in dry $\mathrm{RNase}$ by radiation.

\section{METHODS}

\section{Determination of Enzyme Activity}

Two groups of experiments were carried out with two RNase preparations of different purity, and with different assay techniques.

The first group of experiments was carried out with five-times-crystallized bo- 
vine pancreatic RNase (Sigma Chemical Co., St. Louis, Missouri). Samples were prepared by sealing weighed amounts of the enzyme in small Pyrex tubes under the environment specified in the experiment. The oxygen-free samples either were sealed in a vacuum under a pressure of less than $0.05 \mathrm{~mm} \mathrm{Hg}$ or were filled to about $500 \mathrm{~mm} \mathrm{Hg}$ pressure with dry "highest purity"1 $\mathrm{N}_{2}$ (Ohio Chemical Co., Madison, Wisconsin). After being irradiated, the samples were broken open under a solution of $0.1 M$ tris (hydroxymethyl)aminoethane buffer at $\mathrm{pH}$ 7.0. The activity of the RNase was assayed by the spectrophotometric method of Crook et al. (6) in which the rate of hydrolysis of cytidine $2^{\prime}, 3^{\prime}$-cyclic phosphate (Schwarz Bioresearch Inc., Mount Vernon, New York) by the enzyme is measured. This reaction was followed by observing the change in transmission at $284 \mathrm{~m} \mu$ on a Beckman DK recording spectrophotometer. The criterion for radiation damage was the loss in activity of the enzyme, as measured by the maximum reaction rate.

Some difficulty was experienced in obtaining consistent results with the spectrophotometric technique, so a second group of experiments was performed. For these experiments, RNase purified by chromatography (Sigma Chemical Co.) was used. Samples were prepared by injecting accurately known volumes of a $0.12 \mathrm{M} \mathrm{KCl}$ solution containing $20 \mathrm{mg}$ of RNase per milliliter into the sample tubes and freezedrying the contents for 6 hours or more at a pressure of $0.1 \mathrm{~mm} \mathrm{Hg}$. The tubes were then sealed off, irradiated, broken open under a $0.12 \mathrm{M} \mathrm{KCl}$ solution, and raised to a $\mathrm{pH}$ of 7.0. The activity of the enzyme was measured by a titration method (7) again with cytidine $2^{\prime}, 3^{\prime}$-cyclic phosphate as the substrate. During the reaction a Titrograph $\mathrm{pH}$-stat meter (Radiometer, Copenhagen) automatically added and recorded the correct volume of $\mathrm{NaOH}$ to keep the $\mathrm{pH}$ constant. The initial rate of addition of $\mathrm{NaOH}$ was found to be directly proportional to enzyme concentration over a range of concentrations from 5 to $50 \mu \mathrm{g}$ of enzyme per milliliter of solution. The most satisfactory curves were obtained at a substrate concentration of 0.2 $\mathrm{mg} / \mathrm{ml}$ and an enzyme concentration of $20 \mu \mathrm{g} / \mathrm{ml}$. The absorption of $\mathrm{CO}_{2}$ from the air caused a slow, reproducible drift in the base line for which a correction was made.

\section{Radiation Dosimetry}

The samples were irradiated at a temperature of about $15^{\circ} \mathrm{C}$ close to a 3500 curie $\mathrm{Co}^{60}$ source at a dose rate of about $90,000 \mathrm{rads} / \mathrm{min}$. The $\gamma$-ray dose rate was measured with the ferrous ammonium sulfate dosimeter (8) in a glass vial having approximately the same thickness as the irradiation tubes. The calibration of this system was checked at lower dose rates against a standardized ionization chamber and found to agree very well with a $G$ value for ferric ion production of 15.5 ions per 100 ev absorbed.

${ }^{1}$ Less than 40 parts per million $\mathrm{O}_{2}$. 


\section{Electron Spin Resonance Spectra}

The stable free radicals produced in the irradiated enzyme were detected by an electron spin resonance (ESR) spectrometer. This instrument operates at 9400 $\mathrm{mc} / \mathrm{sec}$ and uses a magnetic field modulation system operating at $450 \mathrm{kc} / \mathrm{sec}$. The unbalanced signal from a microwave bridge is detected and amplified at $450 \mathrm{kc} / \mathrm{sec}$, passed through a phase-sensitive detector, and the output fed to a strip-chart recorder. Samples for the ESR observations were prepared in the same way as those for the biochemical assay and were sealed in $20-\mathrm{cm}$-long glass tubes. In order to eliminate interference from radicals produced in the glass, one end of the tube was shielded during the irradiation, and then the sample was shaken into the shielded end for observation. Because of the difficulty in shielding one end from $\mathrm{Co}^{60} \gamma$-rays, most irradiations were given with a 280-kv X-ray beam having a HVL of $1.1 \mathrm{~mm}$ $\mathrm{Cu}$. In one experiment the $\mathrm{Co}^{60}$ beam was used, and it was found that the same ESR signal was produced by both radiations. The effect of dose on the ESR signal was investigated. The shape of the signal was constant and increased linearly with dose up to doses of 2 Mrads.

\section{RESULTS}

The results of the experiments are summarized in Figs. 1, 2, and 3, which contain data obtained by both assay techniques. There is no significant difference between the two sets of results. In addition, the ESR signals from irradiated ribonuclease samples for one dose are shown in the upper corners of each figure.

\section{Oxygen Effect}

Figure 1 shows the inactivation data for samples irradiated in air (oxygen) and irradiated in vacuum or nitrogen. It should be noted particularly that the vacuum and $\mathrm{N}_{2}$ samples were not exposed to oxygen until after they had been dissolved in the solution. The survival curves obtained were simple exponentials. Comparison of the slopes of the survival curves indicates an oxygen enhancement ratio of $\mathbf{2 . 2}$.

The ESR spectra of irradiated samples of RNase are shown in the upper corner of Fig. 1. The small vertical arrows show the position of the resonance for 1,1diphenyl-2-picrylhydrazyl. The trace gives the first derivative of the absorption lines. The ESR spectrum of RNase irradiated in vacuum showed a characteristic unresolved doublet $(9,10)$ which would be obtained from two Lorentzian lines separated by 10 gauss and each with a half-width of 13 gauss. The second spectrum is that of RNase irradiated in the presence of oxygen. A single resonance was observed with a line width of approximately 19 gauss.

\section{Posttreatment Oxygen Effect}

Experiments were performed to determine whether or not the addition of oxygen after irradiation could also influence the radiosensitivity of the enzyme. This possi- 


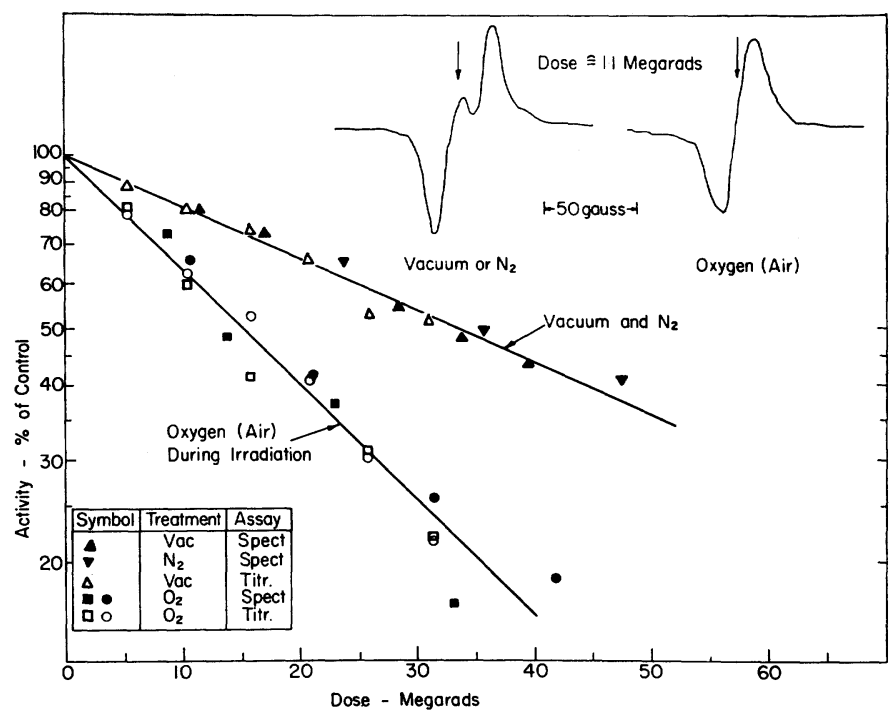

Fig. 1. Survival curves for the enzymatic activity of ribonuclease after exposure of the enzyme to $\mathrm{Co}^{60} \gamma$-rays, for irradiation carried out in vacuum, in the presence of $\mathrm{N}_{2}$, and in the presence of $\mathrm{O}_{2}$. Insert: The ESR spectra of irradiated ribonuclease under these conditions (first derivative).

bility was suggested by the change observed in the ESR spectrum of a sample irradiated in vacuum when oxygen was admitted. As illustrated in Fig. 2, when the sample tube was broken open to admit dry air, the ESR spectrum rapidly changed from the left-hand doublet pattern to the singlet line on the right typical of a sample irradiated in air. This change in the ESR spectrum of RNase on the addition of oxygen has been observed previously (11).

The ESR results suggested that the inactivation of samples irradiated in vacuo and then exposed to air should be measured. The sensitivity obtained in this oxygen "posttreatment" experiment is given by the solid line in Fig. 2. For comparison, the broken lines show the survival curves for irradiation in oxygen and for irradiation in vacuum with nitrogen "posttreatment," which were obtained from Fig. 1. It should be noted that the same sensitization was obtained for samples opened in air (triangular points) or opened under an oxygenated solution (square and circular points). This postirradiation oxygen effect is of considerable importance in determining the course of events in the process of radiation damage and will be discussed in greater detail later.

Effect of Nitric Oxide

Nitric oxide, NO, is a gas which can alter the radiation sensitivity of biological materials, enhancing it in "wet" systems (12) and decreasing it in some dry systems 


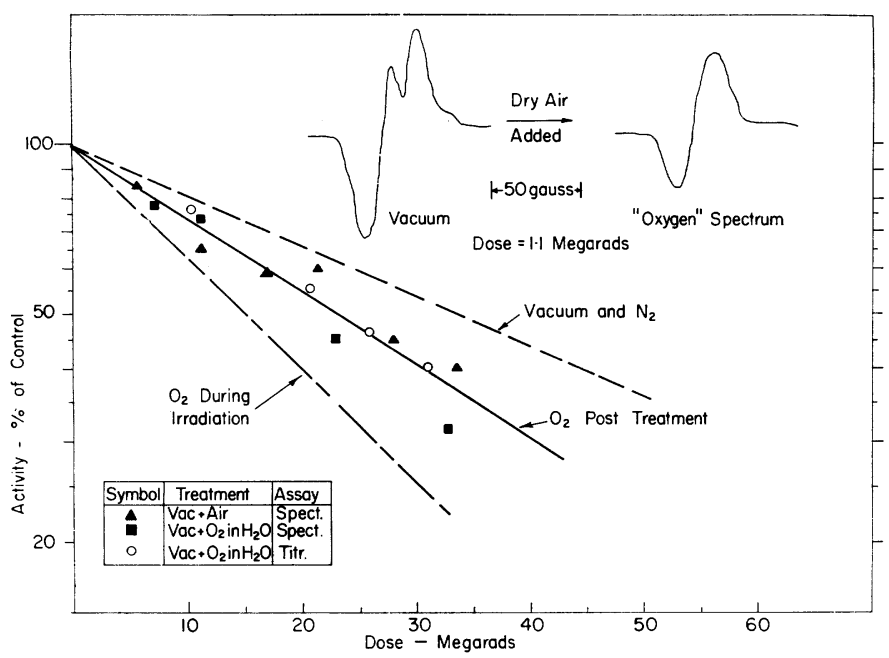

FIg. 2. Survival curve for ribonuclease irradiated in vacuo, then posttreated with oxygen prior to dissolving the enzyme samples for assay. Insert: ESR spectra under these conditions.

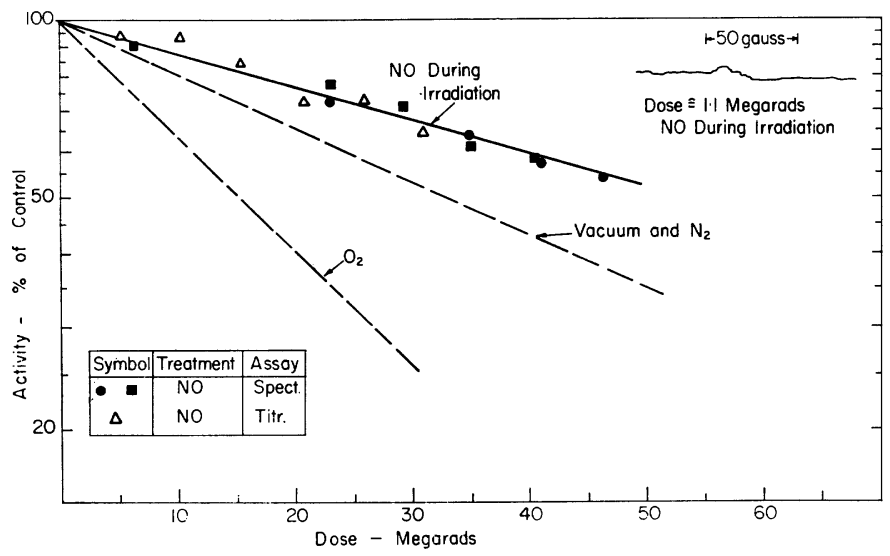

FIG. 3. Survival curve for ribonuclease irradiated in the presence of nitric oxide. Insert: ESR spectrum under this condition.

(3). As may be seen from Fig. 3 , the presence of nitric oxide during the irradiation of ribonuclease considerably protects dry ribonuclease against radiation damage, changing the $\mathrm{D}_{37}$ from 48 to 78 Mrads. (The dotted curves were again obtained from Fig. 1.) No ESR spectrum could be observed for samples irradiated in the presence of nitric oxide. In addition, it was observed that the patterns shown in Fig. 1 rapidly disappeared on the addition of NO.

The results of the experiments described above are summarized in Table I. The 


\section{TABLE I}

Summary of Results Obtained for Ribonuclease Exposed to Co ${ }^{60} \gamma$-Radiation under Various Gaseous Environments

(Dose rate $90,000 \mathrm{rads} / \mathrm{min}$ )

\begin{tabular}{lccc}
\hline Irradiation treatment & $\begin{array}{c}D_{37} \\
(\text { Mrads })\end{array}$ & $\begin{array}{c}G \\
(\text { molecules } / 100 \text { ev })^{\mathrm{a}}\end{array}$ & $G / G_{\text {vac }}$ \\
\hline $\mathrm{O}_{2}$ & 22 & 3.2 & 2.2 \\
$\mathrm{~N}_{2}$ or vacuum & 48 & 1.45 & 1.00 \\
$\mathrm{NO}$ & 78 & 0.89 & 0.61 \\
Vacuum, then $\mathrm{O}_{2}$ & 33 & 2.1 & 1.5 \\
posttreatment & & & \\
\hline
\end{tabular}

a A molecular weight of 13,900 was assumed for ribonuclease.

TABLE II

Oxygen Effect on Dry Enzymes Irradiated with $\gamma$-Rays or Electrons

\begin{tabular}{|c|c|c|c|c|}
\hline Enzymes & $G_{o, o}$ & $G_{v a c, o}$ & Ratio, $G_{o, o} / G_{v a c, o}$ & Ref. \\
\hline Trypsin ${ }^{a}$ & 3.4 & 2.2 & 1.6 & 14 \\
\hline Lysozyme & 2.54 & 1.39 & 1.83 & 15 \\
\hline \multicolumn{5}{|l|}{ Trypsin ${ }^{\mathrm{a}}$} \\
\hline $\begin{array}{l}\text { Film from } 10^{-3} M \\
\mathrm{HCl}\end{array}$ & 4.1 & 4.6 & 0.9 & \\
\hline $\begin{array}{l}\text { Film }+25 \% \text { cysteine } \\
\mathrm{HCl}\end{array}$ & 2.33 & 1.07 & 2.2 & 16 \\
\hline DNase & 1.40 & 0.86 & 1.6 & 17 \\
\hline \multicolumn{5}{|l|}{ Trypsin } \\
\hline $\mathrm{O}_{2}$ pressure $5 \mathrm{~cm} \mathrm{Hg}$ & 1.5 & 0.89 & 1.7 & \\
\hline $\mathrm{O}_{2}$ pressure $42 \mathrm{~cm} \mathrm{Hg}$ & 2.9 & 1.2 & 2.4 & 18 \\
\hline RNase & 3.2 & 2.1 & 1.5 & This paper \\
\hline
\end{tabular}

${ }^{a}$ A molecular weight of $2.38 \times 10^{4}$ was assumed for trypsin (19).

second column gives the $\mathrm{D}_{37}$ obtained from the exponential survival curves for the various irradiation conditions. The third column gives the molecular yields $G$, which represent the number of enzyme molecules inactivated per $100 \mathrm{ev}$ of energy absorbed. These were calculated by using a molecular weight of 13,900 (13) for RNase. The ratios of these yields relative to the yield in nitrogen or vacuum $\left(G_{\mathrm{vac}}\right)$ are shown in the fourth column. 


\section{DISCUSSION}

Several workers have studied the effect of molecular oxygen on the radiosensitivity of dry enzymes. Their results are summarized in Table II. The second column headed $G_{0,0}$ gives the molecular yields per $100 \mathrm{ev}$ absorbed for irradiation in oxygen and posttreatment in oxygen. The third column, $G_{\mathrm{vac}, 0}$, is the yield for irradiation in nitrogen or vacuum with posttreatment in oxygen. In the absence of clarifying statements, it has been assumed that in all these irradiations the samples were dissolved under oxygenated conditions, and hence the results for samples irradiated in the absence of oxygen would correspond to $G_{\mathrm{vac}, 0}$, i.e., an oxygen "posttreatment" situation. The fourth column gives the ratio of $G_{0,0}$ to $G_{\mathrm{vac}, 0}$. It is worthy of note that most of these ratios are of the same order of magnitude, which suggests that there may be a common mechanism for oxygen sensitization of radiation damage in dry enzymes.

The posttreatment oxygen effect which we have observed may be reasonably explained in terms of a free radical model. It may be postulated that the stable free radicals seen in the ESR spectrum are intermediates in the chain of events leading to radiation damage in the enzyme molecule. There is evidence that in vacuo these free radicals may be formed by the removal of a hydrogen atom or a group of atoms from one of the carbon atoms on the polypeptide chain, leaving a free electron associated with a carbon atom (10). In the presence of oxygen, a bi-

radical, a probable reaction would be the formation of a new radical, $-\mathrm{COO}$, which would probably give a single ESR line $(9,12)$. By an unknown mechanism, formation of this radical could lead to an increase in the permanent damage to the enzyme molecules. Providing these carbon radicals are relatively stable, one should obtain an "oxygen effect" whether oxygen is present during the irradiation or added after the completion of the irradiation.

From this point of view, our results suggest that the free radical reactions proceed rapidly to completion when the enzyme samples are dissolved for assay. However, the time required for oxygen to react with the free radicals must be less than the time needed for the radicals to disappear from the solution, since the posttreatment oxygen effect was found to be the same for samples broken open in air and those broken open in oxygenated water. The fact that the posttreatment with oxygen did not produce as large a sensitization as irradiation in oxygen could have been due to the disappearance of some unstable free radicals which decayed before the oxygen was added.

At present, the effect of nitric oxide remains very obscure. Nitric oxide is paramagnetic, like oxygen, but has only one free electron. If nitric oxide reacts with a free radical, the two free electrons could pair up and the ESR spectrum would vanish. No ESR spectrum was in fact observed, but how this process reduces the radiation damage is not known. 
The purity of the enzyme preparation may have an important influence on the results of radiation studies (20). Chromatography of commercial RNase samples on a carboxymethylcellulose column (21) has indicated that several components exist in the five-times-recrystallized samples, whereas much smaller amounts of impurity have been detected in the chromatographed preparations obtained from Sigma Chemical Co. Although both commercial preparations have shown the same radiation sensitivity, preliminary studies on samples extensively purified by chromatography in our laboratory have indicated that the traces of impurity in the commercial preparations may still influence the degree of radiation damage. Experiments are in progress to test the effect of impurities in more detail.

The fact that the results reported here are at least qualitatively similar to those observed in dry bacterial spores (3) suggests that a fundamental and early step in the radiation action is being influenced by oxygen and nitric oxide. The role of the nucleic acid as a key target for radiation damage in living cells appears to be well substantiated (22), but this does not rule out the possibility that radiation effects on the protein moiety of nucleoprotein may also be important. On the other hand, certain similar radical species may play an important role in the action of radiation on both nucleic acids and proteins.

Experiments by Tallentire and Davies (23), using irradiated spores, have indicated that bound water may play an extremely important role in the radiation sensitivity of dry bacterial spores. In our experiments, the procedure for preparation of enzyme samples for irradiation (exposure to a pressure of $10^{-2} \mathrm{~mm} \mathrm{Hg}$ for 20 minutes) may not have removed all the bound water in the enzyme sample. Experiments are under way at present to test for the effect of this bound water on the inactivation of $R$ Nase by radiation.

\section{SUMMARY}

The effect of gaseous environment on the radiation sensitivity of dry ribonuclease has been examined. An oxygen effect was observed, similar in magnitude to that reported by other workers for enzymes irradiated in the dry state. Exposure of the enzyme to oxygen after irradiation under anoxic conditions yielded a reduction in enzymatic activity. Nitric oxide present during irradiation under anoxic conditions had a protective effect.

Changes in the ESR spectrum were observed in every treatment which resulted In a change in the sensitivity of enzymatic activity, suggesting that a correlation exists between the stable free radicals produced in the irradiated enzyme and the effect of radiation on the activity of the enzyme.

\section{ACKNOWLEDGMENTS}

We wish to thank Mr. M. A. Lynch for carrying out the spectrophotometric assays and $\mathrm{Mr}$. J. Polcz for able technical assistance with the ESR measurements. This work was supported in part by the Medical Research Council (Grants MRC 1043 and 1093) and in part by the National Cancer Institute of Canada.

RECEIved: January 5, 1962 


\section{REFERENCES}

1. W. GoRDY, Electron spin resonance of free radicals in irradiated biochemicals. Radiation Research Suppl. 1, 491-510 (1959).

2. J. S. Kirby-Smith and M. L. Randolph, Modification of radiation-induced electron spin resonances in dry materials. J. Cellular Comp. Physiol. 58, Suppl. 1, 1-11 (1961).

3. E. L. Powers, R. B. Webs, and C. F. Ehret, Storage, transfer and utilization of energy from $\mathrm{X}$-rays in dry bacterial spores. Radiation Research Suppl. 2, 94-121 (1960).

4. K. G. Zimmer, Evidence for free-radical production in living cells exposed to ionizing radiation. Radiation Research Suppl. 1, 519-529 (1959).

5. A. D. Conger, Biological after-effect and long-lived free radicals in irradiated seeds. J. Cellular Comp. Physiol. 58, Suppl. 1, 27-32 (1961).

6. E. M. Crook, A. P. Mathias, and B. R. Rabin, Spectrophotometric assay of bovine pancreatic ribonuclease by the use of cytidine $2^{\prime}, 3^{\prime}$-phosphate. Biochem. J. 74, 234-238 (1960).

7. J. P. Hummel, M. Flores, and G. Nelson, Anionic polymers. II. Inhibition of ribonuclease. J. Biol. Chem. 233, 717-721 (1958).

8. Report of the International Commission on Radiological Units and Measurements (ICRU) 1959. Natl. Bur. Standards Handbook No. 78, pp. 54-58 (1961).

9. W. GoRDY and H. SHIELDS, Electron spin resonance studies of radiation damage to proteins. Radiation Research 9, 611-625 (1958).

10. W. Gordy and H. ShIELDs, Structure and orientation of free radicals formed by ionizing radiations in certain native proteins. Proc. Natl. Acad. Sci. U.S. 46, 1124-1136 (1960).

11. H. SHIELDS and W. GoRDY, Electron spin resonance studies of radiation damage to the nucleic acids and their constituents. Proc. Natl. Acad. Sci. U.S. 45, 269-281 (1959).

12. P. Howard-Flanders and P. Jockey, Similarities in the effects of oxygen and nitric oxide on the rate of inactivation of vegetative bacteria by X-rays. Radiation Research 13, 466478 (1960).

13. C. H. W. Hirs, S. Moore, and W. H. Steiv, The sequence of the amino acid residues in performic acid oxidized ribonuclease. J. Biol. Chem. 235, 633-647 (1960).

14. P. ALEXANDER, Effect of oxygen on inactivation of trypsin by the direct action of electrons and alpha particles. Radiation Research 6, 653-660 (1957).

15. R. J. Shalek and T. L. Gillespie, Influence of oxygen upon the radiation damage of lysozyme. In Radiation Biology and Cancer, pp. 41-50, University of Texas, M. D. Anderson Hospital, University of Texas Press, Austin, 1959.

16. J. A. V. Butler and A. B. RoBins, Effect of oxygen on the inactivation of trypsin by ionizing radiation. Nature 186, 697-698 (1960).

17. S. OKada and G. L. Fletcher, Radiation inactivation of deoxyribonuclease in the dry and hydrated states. Radiation Research 13, 92-98 (1960).

18. F. Hutchinson and E. Watts, The effect of oxygen and some other gases on the radiation sensitivity of dry trypsin. Radiation Research 14, 803-812 (1961).

19. P. Desnuelle, Trypsin. In The Enzymes (P. D. Boyer, H. Lardy, and K. Myrbäck, eds.), 2nd ed., Vol. 4, Chapter 6, pp. 119-132, Academic Press, New York, 1960.

20. R. BraAms, F. Hutchinson, and D. RaY, Changes in the sensitivity of enzymes in the dry state to radiation. Nature 182, 1506 (1958).

21. G. TABoRSKy, Chromatography of ribonuclease on carboxymethyl cellulose columns. J. Biol. Chem. 234, 2652-2656 (1959).

22. W. SZYBalski and Z. Opara-Kubinska, DNA as principal determinant of cell radiosensitivity. (Abstract) Radiation Research 14, 508-509 (1961).

23. A. Tallentire and D. J. G. Davies, A postirradiation oxygen effect in bacterial spores and its dependence on water content. Exptl. Cell Research 24, 148-150 (1961). 